\title{
INFLUÊNCIA DA RELAÇÃO GEOMÉTRICA DO REATOR DE LEITO FIXO NA PRODUÇÃO CONTÍNUA DE BIODIESEL ENZIMÁTICO EM MEIO ISENTO DE SOLVENTE
}

\author{
L. RAMOS ${ }^{1}$, L. F. TEIXEIRA ${ }^{1}$, P. C. OLIVEIRA ${ }^{1}$ e H. F. DE CASTRO ${ }^{1}$ \\ ${ }^{1}$ Escola de Engenharia de Lorena-USP(EEL-USP), Departamento de Engenharia Química \\ E-mail para contato: lucas.eng12@usp.br
}

\begin{abstract}
RESUMO - O presente trabalho teve como objetivo avaliar a influência da razão entre a altura $(l)$ e o diâmetro $(d)$ do reator de leito fixo na etanólise do óleo de macaúba catalisada pela lipase de Burkholderia cepacia imobilizada em sílica-PVA. As reações foram operadas continuamente por 20 dias, utilizando óleo: etanol numa razão molar de 1:12 na ausência de solvente e tempo espacial de $14 \mathrm{~h}$. Dois reatores foram testados: Reator I ( $l=55 \mathrm{~mm}$ e $d=15 \mathrm{~mm})$ e Reator II $(l=210 \mathrm{~mm}$ e $d=14$ $\mathrm{mm}$ ), apresentando relação geométrica $l / d$ de 3,7 e 15 , respectivamente. O melhor desempenho foi obtido pelo sistema experimental que empregou o reator II, atingindo $89,7 \pm 4,8 \%$ de rendimento e 40,4 $\pm 2,2 \mathrm{mg} / \mathrm{g} . \mathrm{h}$ de produtividade, enquanto que o sistema operacional que utilizou o reator I forneceu rendimento de $83,9 \pm 4,4 \%$ e 38 $\mathrm{mg} / \mathrm{g} . \mathrm{h}$ de produtividade. Esses dados comprovam a influência das dimensões da coluna empacotada na produção de biodiesel, observando-se que, nas condições testadas, a maior razão não interferiu na transferência de massa do fluido através do reator de coluna.
\end{abstract}

\section{INTRODUÇÃO}

A síntese de biodiesel a partir da transesterificação enzimática de óleos vegetais oferece consideráveis vantagens, incluindo menor consumo de energia, obtenção de produtos com maior grau de pureza, fácil recuperação do glicerol e diminuição da poluição causada por processos químicos convencionais, tornando o processo enzimático uma alternativa promissora a catálise homogênea alcalina (De Castro et al., 2010; Christopher et al., 2014). Esta opção quando associada ao uso de etanol como agente acilante pode tornar a produção de biodiesel um processo totalmente inserido nos conceitos de rotas ambientalmente amigáveis, devido a elevada toxicidade do metanol (Brunschwing et al., 2012).

Dependendo do bioprocesso, enzimas imobilizadas são preferidas às enzimas livres, devido a estabilidade da enzima ligada ao suporte, o que facilita os processos de recuperação e purificação do produto, pois reduz a contaminação do produto pela enzima, permite o uso repetido do biocatalisador, possibilita o desenvolvimento de processos contínuos e portanto, mais econômicos e permite a interrupção rápida da reação a partir da fácil remoção da enzima do meio reacional (Christopher et al., 2014). 


\section{9 a 22 de outubro de 2014 \\ Florianópolis/SC}

A seleção do tipo de biorreator a ser utilizado em processos com enzimas imobilizadas depende da análise criteriosa de uma série de fatores, tais como: (a) a forma da enzima imobilizada - partículas, membranas, fibras; (b) a natureza do substrato - solução, sólidos em suspensão, coloidal; (c) requisitos operacionais da reação - controle de $\mathrm{pH}$, temperatura; (d) cinética da reação - inibição por substrato, produto, ou ambos; (e) a superfície catalítica por unidade de volume de reator; (f) características de transferência de massa externa e interna; (g) facilidade de substituição do catalisador e sua regeneração; (h) facilidade de construção do biorreator; e (i) custo do biorreator (Zanin, Moraes, 2004).

Os reatores de tanque agitado (STR) e de leito fixo (PBR) são as configurações de reatores mais comumente empregadas em processos multifásicos, como por exemplo, na síntese de biodiesel empregando lipases imobilizadas. Em larga escala a produção é normalmente realizada em STR, devido à sua facilidade de construção e operação (Balcão et al., 1996). Esta configuração apresenta, entretanto, algumas desvantagens, uma vez que os sistemas imobilizados não podem ser carregados em grande quantidade e são susceptíveis à quebra devido às altas tensões de cisalhamento impostas pela agitação mecânica, reduzindo a possibilidade de reutilização da enzima imobilizada e consequentemente a viabilidade econômica do processo (Zanin, Moraes, 2004). Assim, reatores de leito fixo tornam-se mais atrativos, devido a sua alta eficiência, baixo custo, facilidade de construção, operação, ampliação de escala, controle automático e menor grau de cisalhamento (Balcão et al., 1996; Wang et al., 2011; Silva et al., 2014). No entanto, essa configuração, pode ser mais influenciada por limitações de transferência de massa e calor, refletida, por exemplo, pela relação geométrica do reator (Xu et al., 2000).

Nesse contexto, o presente trabalho teve como objetivo avaliar o desempenho de um sistema de produção contínua de biodiesel enzimático a partir do óleo de macaúba, empregando reator de leito fixo com diferentes relações geométricas $(l / d)$, visando aumentar a conversão em ésteres de etila.

\section{MATERIAIS E MÉTODOS}

\subsection{Materiais}

Os experimentos foram realizados com a lipase de Burkholderia cepacia adquirida na forma solúvel da Amano Enzyme Inc. (Japão) e posteriormente imobilizada em suporte híbrido de sílica-PVA preparado pela técnica sol-gel (Da Rós et al., 2010), resultando em derivados imobilizados com atividade hidrolítica média de $20563 \pm 52 \mathrm{U} / \mathrm{g}$. Como materiais de partida foram utilizados: etanol anidro (99,5\%, Cromoline) e óleo da amêndoa de macaúba adquirido da Paradigma Óleos Ltda (Carmo da Parnaíba - MG), apresentando composição aproximada em ácidos graxos de: 6,2\% Octanóico, 5,3\% Decanóico, 43,6\% Láurico, 8,5\% Mirístico, 5,3\% Palmítico, 2,4\% Esteárico, 25,5\% Oléico e 3,3\% Linoléico e massa molecular de 716,47 g.mol ${ }^{-1}$.

\subsection{Síntese de biodiesel em reator de leito fixo operado em modo contínuo}

As sínteses de biodiesel a partir da etanólise do óleo de macaúba foram realizadas em colunas de vidro encamisadas com capacidade de $10 \mathrm{~mL}$ (diâmetro interno $=15 \mathrm{~mm}$ e comprimento $=55 \mathrm{~mm}$ ) e $32 \mathrm{~mL}$ (diâmetro interno $=14 \mathrm{~mm}$ e comprimento $=210 \mathrm{~mm}$ ), 
designadas como Reator I e Reator II, respectivamente. A mistura reacional contendo óleo da amêndoa de macaúba e etanol numa razão molar de 1:12 (óleo: etanol) foi mantida em um frasco de alimentação, sob agitação magnética $(150 \mathrm{rpm})$ e temperatura de $50^{\circ} \mathrm{C}$. O substrato foi bombeado através do reator de leito fixo com o auxílio de uma bomba peristáltica (SJ-1211-Atto) na vazão correspondendo a um tempo espacial de 14 horas. Para evitar perda de etanol no sistema, foi acoplado um condensador de refluxo ao frasco de alimentação. Em cada experimento a coluna foi empacotada com suspensão do derivado imobilizado no meio reacional e em seguida estabilizada pela circulação do substrato através da coluna por um período equivalente a 3 tempos espaciais. Amostras diárias foram recolhidas e estocadas a $-2^{\circ} \mathrm{C}$, para realização de análises cromatográficas, de viscosidade e densidade. Ao final dos experimentos a enzima foi recuperada e lavada com terc-butanol para a remoção de substrato e produtos eventualmente retidos nas partículas da matriz para realização da atividade hidrolítica. $O$ esquema experimental está ilustrado na Figura 1.

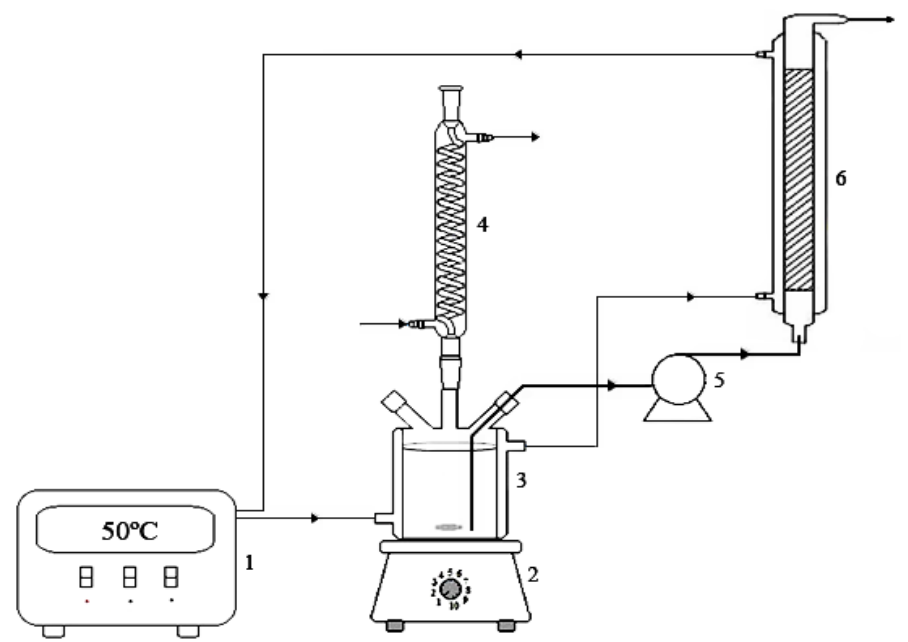

Figura 1 - Esquema experimental do reator de leito fixo. 1- Banho termostatizado; 2- Agitador magnético; 3- Tanque de alimentação; 4- Condensador de refluxo; 5- Bomba peristáltica; 6- Reator de leito fixo.

\subsection{Métodos de Análises}

Atividade hidrolítica: A atividade hidrolítica da lipase imobilizada foi determinada pelo método de hidrólise do azeite de oliva, conforme metodologia modificada por Soares et al. (1999). A constante de desativação térmica do biocatalisador $\left(k_{d}\right)$ e o tempo de meia-vida $\left(t_{1 / 2}\right)$ foram determinados por meio das Equações 1 e 2, respectivamente.

$$
\frac{A}{A_{o}}=e^{-k d . t} \quad \text { (1) } \quad t_{1 / 2}=\frac{\ln 2}{k d}
$$

Em que $\mathrm{A}_{0}$ e $\mathrm{A}$ referem-se, respectivamente, às atividades hidrolíticas inicial e final do biocatalisador. 


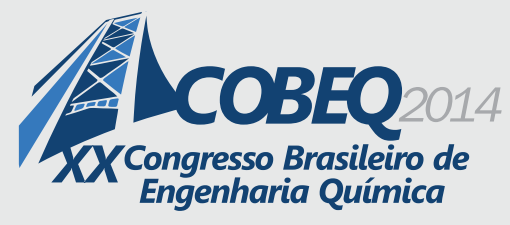

19 a 22 de outubro de 2014
Florianópolis/SC

Dosagem dos ésteres de etila: Os ésteres de etila foram monitorados por cromatografia de fase gasosa (Modelo Varian CG 3800, Inc. Corporate Headquarters, Palo Alto, CA, EUA), conforme metodologia estabelecida por Urioste et al. (2008), empregando amostras previamente tratadas com Lewatit ${ }^{\circ}$ GF202 para remoção do glicerol. O rendimento das transesterificações foi definido como o valor que expressa a massa total obtida de ésteres de etila em relação à massa teórica esperada.

Purificação das amostras de biodiesel: O volume das amostras foi medido e transferido para um funil de decantação, no qual foi adicionado o mesmo volume de água destilada. Efetuou-se uma agitação vigorosa e a mistura foi deixada em repouso por $24 \mathrm{~h}$ para a separação das fases. Esse procedimento foi realizado por três vezes consecutivas. A fase superior composta pelos ésteres de etila (biodiesel) foi submetida à evaporação em rota-evaporador e a fase inferior composta por glicerol e água de lavagem foi descartada.

Dosagem de monoglicerídeos (MAG) e diglicerídeos (DAG): Os teores de MAG e DAG foram quantificados nas amostras de biodiesel purificadas e determinados por cromatografia líquida de alta eficiência, em equipamento Agilent 1200 Series (Agilent Technologies, Inc. SP, Brasil), com detector evaporativo de espalhamento de luz e coluna de aço inoxidável Fenomenex Gemini C18 110 A $(150 \times 4,6 \mathrm{~mm})$ (Allcrom, Ltd., SP, Brasil), nas seguintes condições: temperatura da coluna de $40{ }^{\circ} \mathrm{C}$ e do detector de $70{ }^{\circ} \mathrm{C}$. As fases móveis utilizadas foram: acetonitrila (A) e metanol (B) numa proporção de $80 \%$ A e $20 \%$ B por 35 min em diferentes taxas de fluxo: 1 $\mathrm{mL} / \mathrm{min}(6 \mathrm{~min}) ; 1,5 \mathrm{~mL} / \mathrm{min}(24 \mathrm{~min})$ e $3,0 \mathrm{~mL} / \mathrm{min}(5 \mathrm{~min})$. Todas as amostras foram dissolvidas em acetato de etila-hexano (1:1, v/v) e o volume de injeção foi de $10 \mu \mathrm{L}$.

Determinação da viscosidade e densidade do biodiesel: Os valores da viscosidade absoluta dos produtos purificados foram medidos em viscosímetro Brookfield Modelo LVDVII (Brookfield Viscometers Ltd, Inglaterra) empregando o cone CP 42. As medidas foram realizadas a $40{ }^{\circ} \mathrm{C}$ empregando 1,0 mL de fluido. A densidade dos ésteres de etila foi determinada em densímetro digital Modelo DMA 35N EX (Anton Paar). As medidas foram realizadas a $15^{\circ} \mathrm{C}$ utilizando 5 mL de amostra.

\section{RESULTADOS E DISCUSSÃO}

Estudos de reações catalisadas por lipases imobilizadas em reator de leito fixo têm mostrado que a taxa de reação é afetada pela variação de fluxo linear do fluido. Assim, limitações de transferência de massa, seja entre os reagentes do meio reacional para o sítio ativo da lipase ou do transporte ineficiente do produto para a mistura, são fatores plausíveis de investigação nesta configuração de reator (Xu et al., 2000). Trabalhos descritos na literatura indicam que colunas que apresentam maior relação altura/diâmetro $(l / d)$ sofrem menor limitação de transferência de massa (Damstrup et al., 2007).

Nesse contexto, visando verificar a influência da relação geométrica $(l / d)$ da coluna de leito fixo na síntese de biodiesel contínua do óleo de macaúba empregando lipase $B$. cepacia imobilizada em sílica-PVA, foram efetuados testes em dois reatores apresentando as seguintes 
dimensões: Reator I ( $l=55 \mathrm{~mm}$ e $d=15 \mathrm{~mm}$ ) e Reator II ( $l=210 \mathrm{~mm}$ e $d=14 \mathrm{~mm})$, expressando relação geométrica $l / d$ de 3,7 e 15 , respectivamente. Buscou-se manter um carregamento constante entre a massa de biocatalisador $(\mathrm{g}) /$ volume total do reator $(\mathrm{mL})$, sendo constatado carregamento de $75 \%$ no Reator I e $82 \%$ no Reator II. O perfil de formação dos ésteres de etila em função do tempo de reação está ilustrado na Figura $2(a, b)$.

Verifica-se que em ambos os testes, a formação dos ésteres de etila apresentou correlação com os principais ácidos graxos presentes na composição do óleo de macaúba, sendo evidenciado valores mais elevados do éster laurato de etila $(\mathrm{C} 12)$. $\mathrm{O}$ valor médio obtido em concentração mássica de ésteres foi de 54,8 $\pm 3,3$ e 56,6 $\pm 3,0 \mathrm{~g} / \mathrm{g} \%$, respectivamente para o Reator I e II.
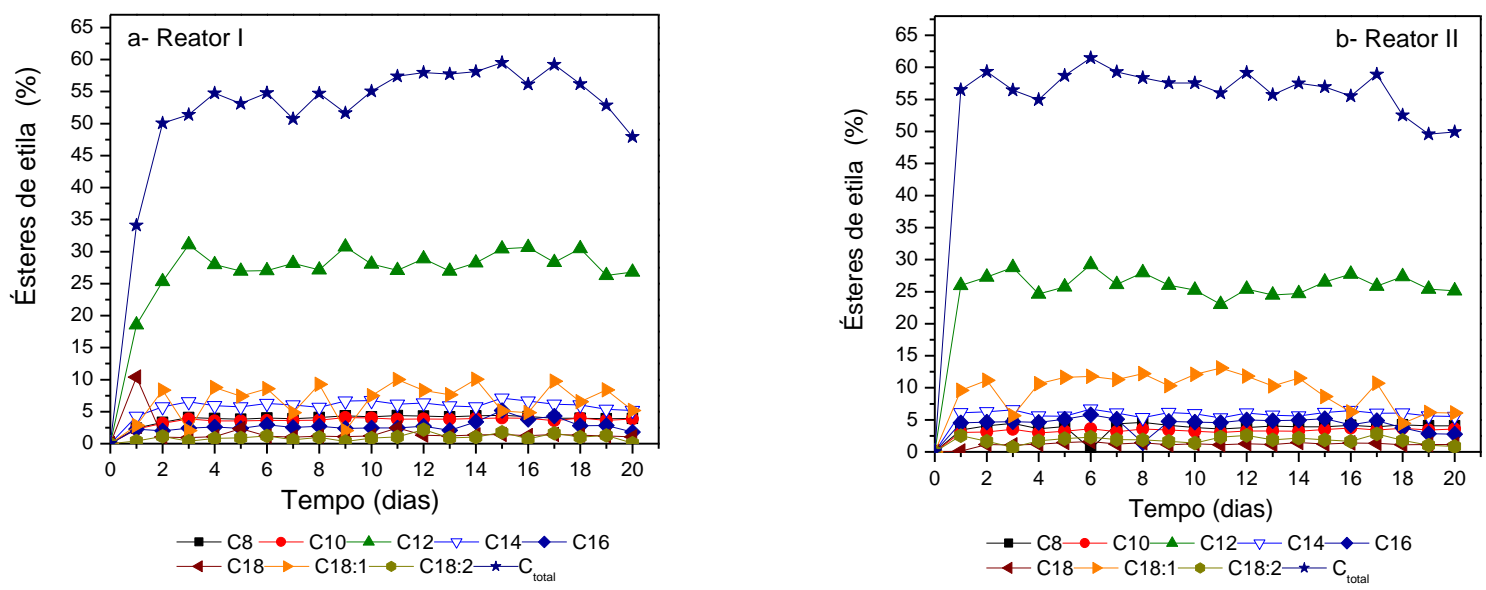

Figura 2 - Perfil de formação dos ésteres de etila na etanólise contínua do óleo de macaúba em reator de leito fixo, empregando diferentes relações geométricas $(l / d)$ : a) Reator I e b) Reator II.

A Figura 3 ilustra que a alteração da relação geométrica $(l / d)$ nos reatores de leito fixo interferiu no rendimento de transesterificação que variou, após o alcance do estado estacionário, de 75,9 a 91,0\% para o teste que empregou razão de 3,7 e de 89,1 a 94,0\% para a razão de 15 . Os sistemas contínuos foram operados por 20 dias, sendo o regime estacionário alcançado em $72 \mathrm{~h}$ (5 tempos espaciais) no sistema experimental que empregou o Reator I e em 48h (3 tempos espaciais) no Reator II, demonstrando melhor estabilidade operacional. Além disso, nessa condição, foi alcançada uma produtividade média de 40,4 $\pm 2,2 \mathrm{mg}_{\text {éster }} \cdot \mathrm{g}^{-1}{ }_{\text {meio }} \cdot \mathrm{h}^{-1}$, superior a obtida pelo Reator I $\left(37,7 \pm 4,2 \mathrm{mg}_{\text {éster }} \cdot \mathrm{g}^{-1}\right.$ meio $\left.\cdot \mathrm{h}^{-1}\right)$.

Destaca-se ainda que não foram detectados problemas de estabilidade operacional relacionados ao desempenho do reator, sendo obtido tempo de meia-vida satisfatório para os biocatalisadores utilizados em ambos os testes. A Tabela 1 resume o desempenho dos biorreatores na etanólise contínua do óleo de macaúba. 


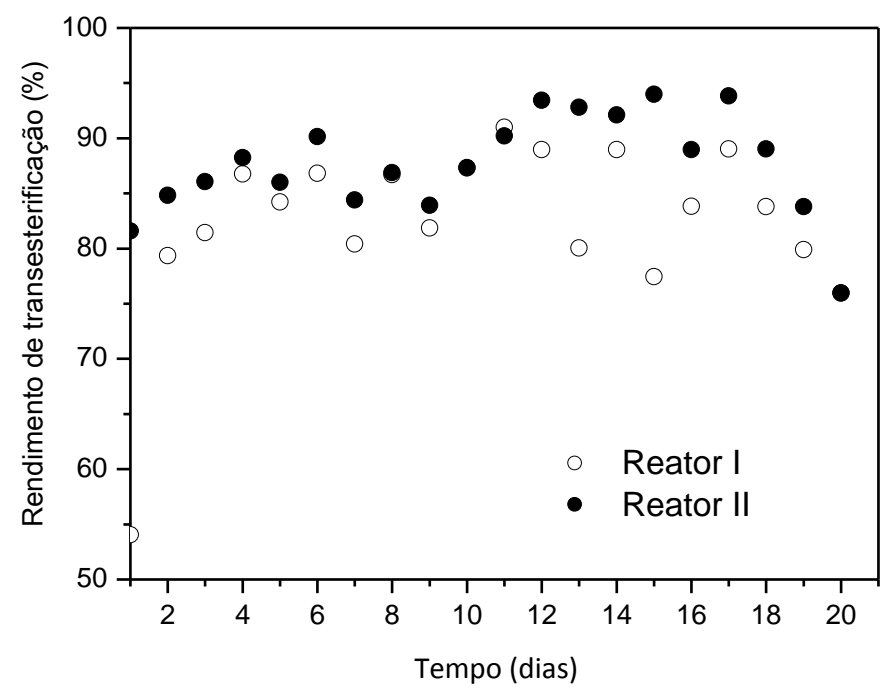

Figura 3 - Rendimento da produção de ésteres de etila em função do tempo reacional na etanólise contínua do óleo de macaúba realizada em reator de leito fixo.

Tabela 1 - Quadro comparativo do desempenho do reator de leito fixo na etanólise contínua do óleo de macaúba mediada pela lipase $B$. cepacia imobilizada em sílica-PVA

\begin{tabular}{lcc}
\hline \multicolumn{1}{c}{ Parâmetros } & Reator $\mathbf{I}(\boldsymbol{l} / \boldsymbol{d}=\mathbf{3 , 7})$ & Reator II $(\boldsymbol{l} / \boldsymbol{d}=\mathbf{1 5 , 0})$ \\
\hline Atividade inicial do biocatalisador $\left(\mathrm{U}_{\mathrm{g}} \mathrm{g}^{-1}\right)$ & $1655 \pm 52$ & $2155 \pm 63$ \\
Atividade residual do biocatalisador $\left(\mathrm{U}^{-1}\right)$ & $613 \pm 39$ & $856 \pm 25$ \\
Constante de desativação $\left(\mathrm{k}_{\mathrm{d}}, \mathrm{h}^{-1}\right) \times 10^{3}$ & 1,7 & 1,9 \\
Tempo de meia-vida (h) & 402 & 358 \\
Concentração de ésteres de etila $\left(\mathrm{g} \cdot \mathrm{g}^{-1}\right)$ & $52,8 \pm 5,9$ & $56,6 \pm 3,0$ \\
Produtividade (mg éster.gmeio $\left.{ }^{-1} \cdot \mathrm{h}^{-1}\right)$ & $37,7 \pm 4,2$ & $40,4 \pm 2,1$ \\
Rendimento de transesterificação $(\%)$ & $83,9 \pm 4,4$ & $89,7 \pm 4,8$ \\
Viscosidade cinemática $40^{\circ} \mathrm{C}\left(\mathrm{mm}^{2} / \mathrm{s}\right)$ & $5,3 \pm 0,63$ & $5,6 \pm 0,62$ \\
\hline
\end{tabular}

De acordo com a Tabela 1, observa-se que o Reator II apresentou melhor desempenho, provavelmente porque os problemas de transferência de massa entre enzima e substrato foram minimizados pela relação geométrica $(l / d=15)$ adequada. Com o intuito de verificar se o produto obtido atendia as especificações da ANP, foram efetuadas análises adicionais às amostras de biodiesel purificadas. A Figura 4 mostra o perfil da concentração de ésteres de etila, monoglicerídeos (MAG) e diglicerídeos (DAG) no produto purificado, obtido a partir da etanólise contínua do óleo de macaúba.

Embora promissores, os resultados mostram que a qualidade do produto final não atendeu a todos os parâmetros exigidos pelas normas competentes, visto que, o Regulamento Técnico da 
ANP ( $\left.{ }^{\circ} 14 / 2012\right)$, especifica um valor mínimo de $96,5 \%$ em massa de ésteres e valores máximos de 0,8 e $0,2 \%$ em massa de MAG e DAG, respectivamente. Uma alternativa para elevar o rendimento do processo e reduzir os teores de MAG e DAG seria o emprego de um segundo reator em série (processo contínuo em duplo estágio), que proporcionaria um incremento na formação de ésteres de etila em relação ao primeiro estágio.

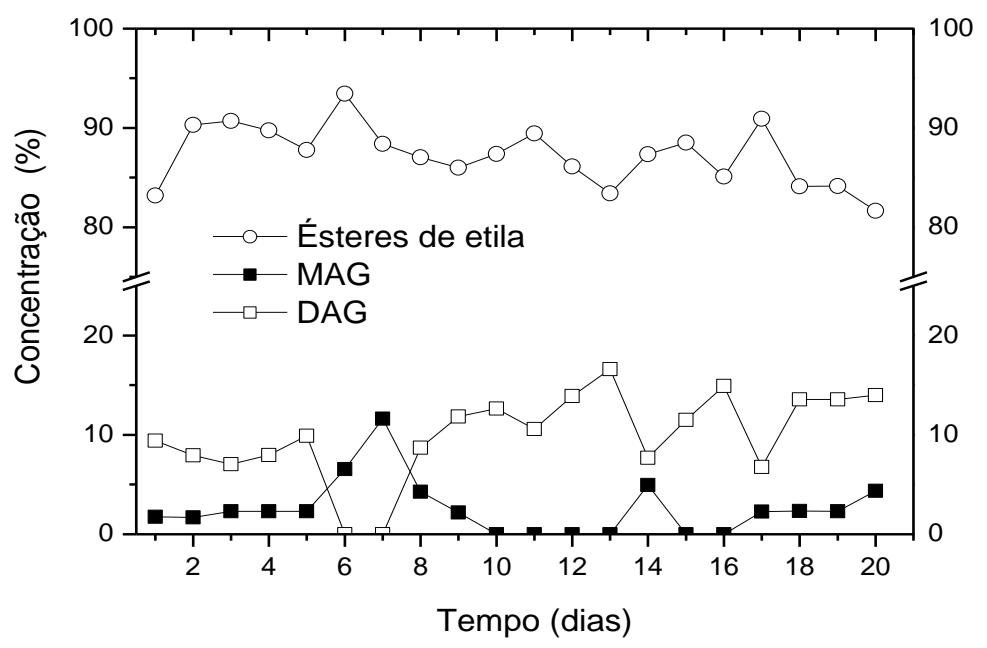

Figura 4 - Relação entre concentração de ésteres de etila, monoglicerídeos e diglicerídeos quantificados no produto purificado obtido em fluxo contínuo (Reator II).

\section{CONCLUSÃO}

Os resultados obtidos indicaram que o sistema experimental que empregou o Reator II (razão $l / d=15$ ), apresentou melhor desempenho na síntese de biodiesel a partir da etanólise contínua do óleo de macaúba. Esse fato pode ser comprovado pelas concentrações mais elevadas de ésteres de etila, da ordem de $56,6 \pm 3,0 \mathrm{~g} / \mathrm{g} \%$, correspondendo a rendimentos médios de 89,7 \pm $4,8 \%$ e produtividade de $40,4 \pm 2,2 \mathrm{mg}_{\text {éster }} \cdot \mathrm{g}^{-1}$ meio $\mathrm{h}^{-1}$. A lipase de $B$. cepacia imobilizada em sílica-PVA demonstrou satisfatória estabilidade operacional, apresentando tempo de meia-vida de $402 \mathrm{~h}$ e a eficiência do sistema experimental foi comprovada pelo alcance do estado estacionário em apenas 3 tempos espaciais. Trabalhos futuros serão realizados com reatores em duplo estágio, visando adequar o produto às especificações da ANP e viabilizar a síntese enzimática de biodiesel a partir de óleo vegetal de composição predominantemente láurica, mediada pela lipase de B. cepacia imobilizada em sílica-PVA em meio isento de solvente operada em modo contínuo.

\section{REFERÊNCIAS}

BALCÃO, V. M.; PAIVA, A. L.; MALCATA, F. X. Bioreactors with immobilized lipases: State of the art. Enzyme Microb. Technol., v. 18, p. 392-416, 1996. 
BRUNSCHWING, C., MOUSSAVOU, W., BLIN, J. Use of bioethanol for biodiesel production. Prog. Energy Combust. Sci., v. 38, p. 283-301, 2012.

CHRISTOPHER, L P.; KUMAR, H.; ZAMBARE, V.P. Enzymatic biodiesel: Challenges and opportunities. Appl. Energy, v.119, p. 497-520, 2014.

DAMSTRUP, M.; KIIL. S.; JESE, A. D.; SPARSO, F. D.; XU, X. Process development of continuous glycerolysis in an immobilized enzyme-packed reactor for industrial monoacylglycerol production, J. Agric. Food Chem., v.55, p. 7786-7792, 2007.

DA RÓS, P. C. M.; SILVA, G. A. M.; MENDES, A. A.; SANTOS, J. C.; DE CASTRO. H. F. Evaluation of the catalytic properties of Burkholderia cepacia lipase immobilized on noncommercial matrices to be used in biodiesel synthesis from different feedstocks. Bioresour. Technol., v. 101, p. 5508-5516, 2010.

DE CASTRO, H. F.; MENDES, A. A.; FREITAS, L; SANTOS, J. C. Modificação enzimática de óleos e gorduras para a obtenção de biocombustíveis e produtos de interesse do setor alimentício. In: MARSAIOLI, A.J., PORTO, A.L.M. Biocatálise e Biotransformação: Fundamentos e Aplicação. Salto, Brasil: Schoba. v.1, p. 275-317, 2010.

SILVA, W. C.; TEIXEIRA, L. F.; CARVALHO, A. K.F.; MENDES, A. A. DE CASTRO, H. F. Influence of feedstock source on the biocatalyst stability and reactor performance in continuous biodiesel production. J. Ind. Eng. Chem., v. 20, p. 881-886, 2014.

SOARES, C. M. F.; CASTRO, H. F.; MORAES, F. F.; ZANIN, G. M. Characterization and utilization of Candida rugosa lipase immobilized on controlled pore silica. Appl. Biochem. Biotechnol., v.77-9, p. 745-757, 1999.

URIOSTE, D.; CASTRO, M. B. A.; BIAGGIO, F. C.; DE CASTRO, H. F. Síntese de padrões cromatográficos e estabelecimento de método para dosagem da composição de ésteres de ácidos graxos presentes no biodiesel a partir do óleo de babaçu. Quim. Nova, v. 31, p. 407412, 2008.

XU X.; FOMUSO, L. B.; AKOH, C. C. Production of specific-structured triacylglycerols by lipase-catalyzed reactions: a review. Eur. J. Lipid. Sci. Technol., v. 48, p. 287-303, 2000.

WANG, X.; LIU, X.; ZHAO, C.; DING, Y; XU, P. Biodiesel production in packed-bed reactors using lipase-nanoparticle biocomposite. Bioresour. Technol., v.102, p.6352-6355, 2011.

ZANIN, G. M.; MORAES, F. F. Enzimas Imobilizadas. In SAID, S.; PIETRO, R. C. L. R. Enzimas como agentes biotecnológicos. Ribeirão Preto: Legis Summa, 2004. Cap. 4. p. 3585. 